\title{
Successful implementation of electronic disease reporting in Georgia
}

\author{
Lia Sanodze ${ }^{\star 1}$, Naile Malakmadze ${ }^{2}$, Rusudan Chlikadze ${ }^{1}$, Maka Tsilosani $^{1}$, \\ Tamar Teimurazishvili ${ }^{1}$, Tsira Napetvaridze ${ }^{3}$, Natia Kartskhia ${ }^{3}$ and Khatuna Zakhashvili ${ }^{1}$
}

${ }^{1}$ National Center for Disease Control and Public Health, Tbilisi, Georgia; ${ }^{2}$ Northrop Grumman, Atlanta, GA, USA; ${ }^{3}$ National Food

Agency of Georgia, Tbilisi, Georgia

\section{Objective}

The objective of this study was to evaluate several aspects of the electronic disease reporting system and its abilities used in Georgia. Also, the study assessed if the system abilities are tailored to the national surveillance requirements. User attitudes (system strength and weaknesses) toward the system was also surveyed.

\section{Introduction}

The Ministry of Health of Georgia accepted the Electronic Integrated Disease Surveillance System (EIDSS) as an official disease reporting system in 2012. The Georgian government adopted electronic reporting for both veterinary and human diseases in 2015. We conducted a comparative assessment of progress in the implementation of electronic reporting.

\section{Methods}

A face-to-face initial survey was conducted in 2012, a follow-up survey (through telephone interviews) was performed in 2016. The initial survey was conducted in regions that had EIDSS installed and the follow-up survey was conducted in all regions. Standardized questionnaires were used and data was analyzed in Epi Info.

\section{Results}

Out of 450 trained EIDSS users, 32\% were interviewed in the initial survey and 25\% (of 550) EIDSS trained users were interviewed in the follow-up survey. Of 147 respondents in the initial survey and 138 in the follow-up survey, $44 \%$ and $79 \%$, believed that they were using EIDSS effectively, respectively. The follow-up survey showed a $23 \%$ increase in respondents who acknowledge an improvement of the electronic reporting; acceptance of EIDSS increased from $80.3 \%$ to $97.8 \%$. Of those interviewed in the follow-up survey, $19.7 \%$ mentioned that the main success in development of the system is due to improved collaboration between institutes. However, $17.36 \%$ of the respondents in the follow-up survey reported non-sufficient quality data.

\section{Conclusions}

Our study suggests that the acceptance and use of EIDSS has noticeably improved, indicating the successful implementation of electronic reporting. Recommendations have been made to further improve the data quality by conducting regular data cleaning and additional user training. We recommend the continuation of EIDSS training.

\section{Keywords}

EIDSS; Electronic reporting; Implementation; Assessment; Government regulation

\section{Acknowledgments}

Participation in this conference was made possible by financial support provided by the US Defense Threat Reduction Agency. The findings, opinions and views expressed herein belong to the authors and do not reflect an official position of the Department of the Army, Department of Defense, or the US Government, or any other organization listed.

\author{
*Lia Sanodze \\ E-mail: Lia.Sanodze@gmail.com
}

